STUDI

FRANCESI

\section{Studi Francesi}

Rivista quadrimestrale fondata da Franco Simone

Varia

\title{
SOPHIE VALLERY-RADOT, Les Français au concile de Constance (1414-1418). Entre résolution du schisme et construction d'une identité nationale
}

\section{Paola Cifarelli}

\section{(2) OpenEdition}

Journals

\section{Édition électronique}

URL : http://journals.openedition.org/studifrancesi/16221

DOI : 10.4000/studifrancesi. 16221

ISSN : 2421-5856

Éditeur

Rosenberg \& Sellier

\section{Édition imprimée}

Date de publication : 1 juillet 2019

Pagination : 138

ISSN : 0039-2944

\section{Référence électronique}

Paola Cifarelli, « SoPhIE VAlLeRY-RAdot, Les Français au concile de Constance (1414-1418). Entre résolution du schisme et construction d'une identité nationale », Studi Francesi [En ligne], 187 (LXIII | I) | 2019, mis en ligne le 01 juin 2019, consulté le 25 janvier 2021. URL : http://journals.openedition.org/studifrancesi/ 16221 ; DOI : https://doi.org/10.4000/studifrancesi.16221

Ce document a été généré automatiquement le 25 janvier 2021.

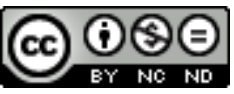

Studi Francesi è distribuita con Licenza Creative Commons Attribuzione - Non commerciale - Non opere derivate 4.0 Internazionale. 


\title{
SOPHIE VALLERY-RADOT, Les Français au concile de Constance (1414-1418). Entre résolution du schisme et construction d'une identité nationale
}

\author{
Paola Cifarelli
}

\section{RÉFÉRENCE}

SOPHIE VALLERY-RADOT, Les Français au concile de Constance (1414-1418). Entre résolution du schisme et construction d'une identité nationale, Turnhout, Brepols, 2016, «Ecclesia Militans» 5, 2 vols, $629+354 \mathrm{pp}$.

Cette vaste étude historique est consacrée à la naissance du concept de 'nation' au sein des membres du Concile de Constance; en effet, on sait que lors du concile convoqué par le pape pisan Jean XXIII en 1414, les pères conciliaires furent réunis en cinq groupements, que l'A. considère comme autant de foyers où le sentiment national dans un sens plus vaste se crée et se renforce progressivement. En suivant le développement des événements au sein du concile selon un ordre chronologique, S. V.-R. identifie minutieusement les différents membres de la nation française, par delà les grandes personnalités bien connues comme Pierre d'Ailly ou Jean Gerson; elle reconstruit surtout les réseaux politiques, religieux, familiaux qui se tissent entre les pères conciliaires représentant le roi de France, ainsi que leur rapport avec les membres venant des autres régions (Lorraine, Savoie, Franche-Comté) et la progression selon laquelle le sentiment d'appartenance à une nation au sens politique du terme germe, puis se renforce et se transforme. Puisque le déroulement du concile est finalement un miroir de la politique européenne contemporaine, et en raison de la nature éminemment culturelle de la problématique qui est au cœur de cette recherche, la présente étude est susceptible d'intéresser aussi les spécialistes de littérature française 
du moyen âge tardif, qui pourront mieux saisir les enjeux des textes qu'ils étudient à la lumière des informations que l'on trouvera réunies ici et des analyses effectuées par l'A.

De plus, la documentation sur laquelle cette étude se fonde est aussi riche que variée; elle est constituée non seulement d'actes de procès, de correspondances, de discours et sermons, mais aussi de sources narratives telles les chroniques, comme celle d'Enguerrand de Monstrelet, ou les journaux (Guillaume Fillastre, Jacobus Cerretanus, Guillaume de la Tour). Dans le premier volume, le travail est structuré en trois parties, qui correspondent aux phases successives dans lesquelles les événements peuvent être regroupés: le début du concile (novembre 1414-mars 1415), avec la construction de la 'nation française' au fil des arrivées, des retards, de la participation des pères conciliaires, de leur provenance et formation, de leur orientation politique; la deuxième partie (mars 1415-janvier 1417), marquée par la fuite du pape à Schaffhouse et les difficultés auxquelles la nation française est confrontée, mais aussi par un renforcement du sentiment national; la troisième partie, consacrée à la phase finale du concile (janvier 1417-conclusion), est marquée entre autres par la trahison de Jean Mauroux et son expulsion de la nation française. L'A. parvient à la conclusion que, malgré la division de celle-ci en factions politiques, «l'affirmation de la fidélité à la couronne et à la foi ainsi que les références à une histoire commune subsistent» (p. 481) et que le concept de 'nation France', supposant une conscience identitaire, commence à devenir familier au sein du groupe des pères. Par delà l'échec de la cause royale et la dissolution de la nation française après le concile, l'A. montre que le modèle conceptuel de la nation continue à vivre. Le concile de Constance est donc considéré comme un moment privilégié de l'émergence d'un sentiment national français sur le plan politique et religieux, ainsi qu'une prémisse pour l'enthousiasme suscité par Jeanne d'Arc onze ans après et pour les revendications en faveur de la liberté de l'Église de France exposées au concile de Pavie en 1423.

3 Le second tome de cet ouvrage est consultable en ligne sur le site de la maison d'édition Brepols; il contient les notices consacrées aux 274 membres de la nation française telles qu'elles ont pu être établies à partir des listes de participants au concile, qui ne sont pas sans poser d'importants problèmes méthodologiques; l'annexe $1 \mathrm{du}$ premier tome discute ces questions en fournissant une intéressante matière de réflexion, tandis que l'annexe 2 fournit sous forme de liste les noms des personnalités traitées dans le deuxième tome.

Véritable mine d'informations, cet ouvrage argumente de manière convaincante une thèse novatrice. 